[2] Narváez J et al.JRheumatol. 2000 Apr;27(4):953-7. Lack of association between infection and onset of polymyalgia rheumatica.

[3] F. Perfetto et al. seasonal pattern in the onset of polymyalgia rheumatic. Abstract EULAR 2005

[4] Chen ZR et al. Epidemiology of community-acquired Mycoplasma Pneumoniae among hospitalized Chinese children.Hippokratia. 2013;17(1):20-26.

[5] Enders $M$ et al. Current epidemiological aspects of human parvovirus B19 infection Epidemiol Infect. 2006;135(4):563-569.

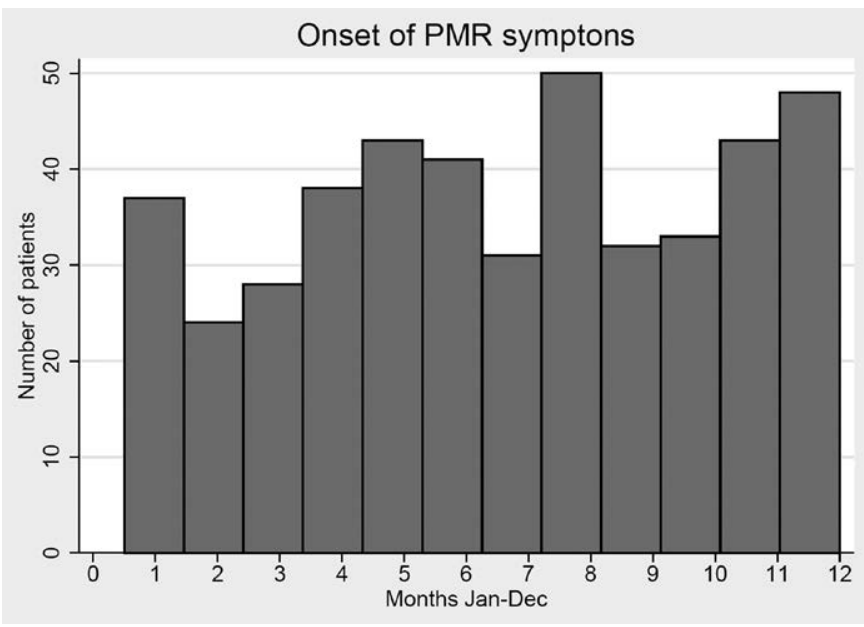

Disclosure of Interests: None declared

DOI: 10.1136/annrheumdis-2020-eular.1717

\section{AB0506 $\quad$ GIANT CELL ARTERITIS: IS ROUTINE CLINICAL PRACTICE COMPREHENSIVE ENOUGH?}

J. Martínez-Barrio $^{1}$, B. Serrano Benavente ${ }^{1}$, T. Del Río Blasco ${ }^{1}$, A. Ariza ${ }^{1}$,

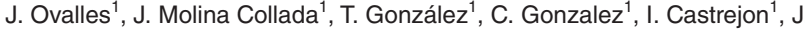
M. Alvaro Gracia'. ' Gregorio Marañón University Hospital, Rheumatology, Madrid, Spain

Background: Recommendations to collect the most relevant information on disease course, treatment and outcomes in giant cell arteritis (GCA) has been proposed by EULAR to facilitate clinical research and to improve clinical care. Objectives: To assess the quality of data collection in routine clinical practice according to EULAR recommendations and to describe baseline and follow-up characteristics of a retrospective cohort of patients with GCA

Table 1. GCA-related signs and symptoms, laboratory and therapeutic data.

\begin{tabular}{lcccc}
\hline Item & $\begin{array}{c}\text { Performed } \\
\text { Baseline }\end{array}$ & $\begin{array}{c}\text { Baseline } \\
\mathrm{n}=39\end{array}$ & $\begin{array}{c}\text { Performed } \\
\text { Follow-up }\end{array}$ & $\begin{array}{c}\text { Follow-up } \\
\mathrm{n}=112\end{array}$ \\
\hline
\end{tabular}

Ocular symptoms

$35 / 39(89.7 \%) \quad 15 / 35(42.9 \%) \quad 91 / 112(81.2 \%) 29 / 91(31.9 \%)$

$\begin{array}{llll}\text { Permanent ocular symptoms } \quad 34 / 39(87 \%) & 9 / 34(26.5 \%) & 92 / 112(82 \%) & 28 / 92(30.4 \%)\end{array}$

Headache

Scalp tenderness

Jaw claudication

Cranial artery abnormality

Constitutional symptoms

PMR

ESR mean (SD)

CRP mean (SD)

Haemoglobin mean (SD)

Peripheral pulses

Large vessel involvement

Glucocorticoids median

(IQR)

Synthetic DMARD

Biological DMARD

Antiplatelet agents

$39(100 \%) \quad 30 / 39(77 \%) \quad 90 / 112(80.4 \%) \quad 13 / 90(14.4 \%)$

$31 / 39(79.5 \%) \quad 9 / 31(29.8 \%) \quad 88 / 112(78.6 \%) \quad 4 / 88(4.5 \%)$

$34 / 39(87 \%) \quad 19 / 34(55.85) \quad 91 / 112(81.2 \%) \quad 6 / 91(6.6 \%)$ $27 / 39(69.2 \%) \quad 17 / 27(63 \%) \quad 69 / 112(61.6 \%) \quad 3 / 69(4.3 \%)$ $35 / 39(89.7 \%)$ 19/35 (54.3\%) 90/112 (80.4\%) $11 / 90(12.2 \%)$ $35 / 39(89.7 \%) \quad 18 / 35(51.4 \%) \quad 92 / 112(82 \%) \quad 9 / 92(9.8 \%)$ $33 / 39(84.6 \%) \quad 58.7(32.1) \quad 83 / 112(74 \%) \quad 14.6(18.8)$ $31 / 39(79.5 \%) \quad 8.4(7.9) \quad 70 / 112(62.5 \%) \quad 1.3(3.3)$ $38 / 39(97.4 \%) \quad 12.0(1.7) \quad 90 / 112(80.4 \%) \quad 12.9(1.5)$ $9 / 39(8 \%) \quad 3 / 9(33.3 \%) \quad 5 / 112(4.5 \%) \quad 2 / 5(40 \%)$ $8 / 39(20.5 \%) \quad 5 / 8(62.5 \%) \quad 7 / 112(6.25 \%) \quad 3 / 7(42.8 \%)$ $39(100 \%) \quad 102.5(50-250) \quad 112(100 \%) \quad 10.0(5-15)$

39 (100\%) $\quad 8 / 39(20.5 \%) \quad 111 / 112(99 \%) \quad 17 / 39(43.6 \%)$ $39(100 \%) \quad 0 / 39(0 \%) \quad 111 / 112(99 \%) \quad 3 / 39(7.7 \%)$ $39(100 \%) \quad 6 / 39(15.4 \%) \quad 110 / 112(98 \%) \quad 25 / 110$

(22.7\%)

PMR: polymyalgia rheumatica, ESR: erythrocyte sedimentation rate, CRP: C-reactive protein, SD: standard deviation, IQR: interquartile range, DMARD: disease modifying antirheumatic drugs
Methods: We reviewed medical records of patients diagnosed with GCA in a tertiary academic center between 2004-2018. We included patients with available data at diagnosis and one year of follow-up. Data extraction included: demographics, diagnosis, GCA-related signs and symptoms, laboratory, imaging modalities, comorbidities and treatment. Data in the chart was then compared with the core set of parameters proposed for GCA registries and databases by EULAR. Major relapse, according to the EULAR 2018 definition, was independently assessed by two rheumatologists.

Results: 58 patients were identified, 39 met predefined inclusion criteria with 151 visits during first-year follow-up. Headache (100\%; $80.4 \%)$, ocular symptoms (89.7\%; 81.2\%), constitutional symptoms (89.7\%; $80.4 \%)$, polymyalgia rheumatica $(89.7 \% ; 82 \%)$ and jaw claudication $(87 \% ; 81.2 \%)$ were the most frequently collected items at baseline and follow-up. Weight and height $(2.6 \%$; $2.6 \%)$, peripheral pulses $(8 \% ; 4.5 \%)$, smoking status $(41 \% ; 21 \%)$, and blood pressure $(61.5 \% ; 4.5 \%)$ were the less frequently collected. Most patients lacked differential pressure measurement. Myocardial infarction, malignancy, serious infections, arterial hypertension, diabetes and osteoporosis were collected in every patient $(39,100 \%)$. Only 2 mayor relapses were identified $(5 \%)$ Two (2) patients died during the one-year follow-up period. Table 1 provides information on GCA-related signs and symptoms, laboratory and therapeutic data.

Conclusion: Although data collection in routine care is usually comprehensive enough according to EULAR proposed data set, key components in physical exam mostly those aiming to detect large vessel involvement, should be addressed more carefully.

References:

[1] Ehlers L, et al. Ann Rheum Dis. 2019;78(9):1160-6.

[2] Hellmich B, et al. Ann Rheum Dis. 2019;1-12.

Disclosure of Interests: Julia Martínez-Barrio Consultant of: UCB Pharma, Belén Serrano Benavente: None declared, Tamara Del Río Blasco: None declared, Alfonso Ariza: None declared, Juan Ovalles: None declared, Juan Molina Collada: None declared, Teresa González: None declared, Carlos Gonzalez Consultant of: Gilead, Janssen, Novartis, Speakers bureau: Abbvie, Celgene, Gilead, Janssen, Novartis, Pfizer, Roche, Isabel Castrejon: None declared, Jose Maria Alvaro Gracia: None declared DOI: 10.1136/annrheumdis-2020-eular.4852

\section{AB0507 RHEUMATOLOGICAL PATIENTS IN SAINT PETERSBURG, RUSSIA.}

V. Mazurov ${ }^{1}$, O. Shadrivova ${ }^{1}$, M. Shostak ${ }^{1}$, L. Martynova ${ }^{1}$, M. Tonkoshkur ${ }^{1}$, N. Klimko'. ${ }^{1}$ North-Western State Medical University named after I.I. Mechnikov, Saint Petersburg, Russian Federation

Background: Invasive aspergillosis (IA) is a severe opportunistic infection that is not well understood in rheumatological patients.

Objectives: To study risk factors, etiology, clinical manifestations and results of treatment of IA in adult rheumatological patients.

Methods: Retrospective analysis of 830 patients (1998-2019) with "proven" and "probable" IA (EORTC / MSG, 2019), adults - 699 (84\%). The main group included $18(3 \%)$ adult rheumatological patients with IA, a control group included $610(87 \%)$ adult hematological patients. Rheumatological patients were older, the average age was 59 years $(21-75)$ vs 45 years $(18-79), p=0.005$, and among them there were more women $-56 \%$ vs $42 \%, p=0.01$.

Results: In rheumatological patients with IA, underlying diseases were ANCA-associated vasculitis (28\%), granulomatosis with polyangiitis $(22 \%)$, periarteritis (11\%), systemic lupus erythematosus $(22 \%)$, rheumatic heart disease $(11 \%)$ and ankylosing spondylitis (6\%). In the control group, underlying diseases were acute leukemia (45\%), lymphomas (34\%), chronic leukemia $(9 \%)$, multiple myeloma $(7 \%)$, myelodysplastic syndrome $(3 \%)$, and other hematological diseases (2\%)

The main risk factors for IA development in rheumatological patients were: systemic steroids use ( $89 \%$ vs $69 \%$ ), prolonged lymphocytopenia (76\% vs $65 \%$, median - 14 vs 12 days), treatment in ICU ( $44 \%$ vs $18 \%, p=0.01)$, acute or chronic renal failure (39\% vs $1 \%, p=0.0008)$ and immunosuppressive therapy ( $28 \%$ vs $25 \%$ ). Severe neutropenia was noted significantly less frequently ( $18 \%$ vs $83 \%, p=0.0001)$. Additional risk factors were decompensated diabetes mellitus $(17 \%$ vs $2 \%, p=0.004)$, previous surgery $(17 \%$ vs $1 \%, p=0.001)$ and organ transplantation ( $6 \%$ vs $0 \%)$. In rheumatological patients, lung $(83 \%$ vs $98 \%, p=$ $0.0001)$ and $\geq 2$ organs ( $6 \%$ vs $8 \%$ ) involvement were less common. Heart ( $11 \%$ vs $0 \%$ ), sinuses $(6 \%$ vs $5 \%$ ) and central nervous system (6\% vs $4 \%$ ) involvement more often developed. In rheumatological patients, respiratory failure $(61$ vs $37 \%, p=0.03)$, hemoptysis $(28 \%$ vs $7 \%, p=0.0001)$ and chest pain $(17 \%$ vs $7 \%, p=0,04)$ were noted more often, less often - fever $\geq 38^{\circ} \mathrm{C}(67 \%$ vs $85 \%$, 
$p=0.01)$ and cough $(61 \%$ vs $70 \%)$. CT signs of lung damage were similar in both groups, but rheumatologic patients were more likely to show an «air crescent» sign and / or destruction cavity ( $44 \%$ vs $10 \%, p=0.0001)$. In rheumatologic patients, IA was more often confirmed by isolation of Aspergillus spp. from BAL $(80 \%$ vs $45 \%, p=0.005)$ and by histological examination ( $22 \%$ vs $7 \%, p=0.01)$. The main pathogens were A. fumigatus ( $50 \%$ vs $43 \%)$, A. niger ( $29 \%$ vs $32 \%)$, and $A$. flavus ( $14 \%$ vs $17 \%)$.

Rheumatological patients were less likely to receive antifungal therapy $89 \%$ vs $99 \%, p=0,0003$. The main drug in both groups was voriconazole. The overall 12-week survival did not significantly differ between groups, but was lower in rheumatological patients with IA (69\% vs $81 \%$ ).

Conclusion: In rheumatological patients, invasive aspergillosis more often developed at an older age, mainly in women. The main background diseases were ANCA-associated vasculitis, granulomatosis with polyangiitis, and systemic lupus erythematosus. Typical risk factors were steroids and immunosuppressants use, prolonged lymphocytopenia, ICU stay, and renal failure. The main causative agents were A. fumigatus, A. niger, and A. flavus. The main localization of infection were lungs. Respiratory failure, hemoptysis and heart involvement were typical. The overall 12-week survival of rheumatological patients with invasive aspergillosis was $69 \%$.

Disclosure of Interests: None declared

DOI: 10.1136/annrheumdis-2020-eular.3796

\section{AB0508 EFFICACY AND SAFETY OF TNF-A ANTAGONISTS AND TOCILIZUMAB IN TAKAYASU ARTERITIS: MULTICENTER EUROPEAN RETROSPECTIVE STUDY OF 203 PATIENTS.}

A. Mekinian ${ }^{1}$, M. Vautier ${ }^{1}$, M. Resche-Rigon ${ }^{1}$, L. Dagna ${ }^{1}$, S. Sciascia ${ }^{1}$, O. E. N. F. Olivier.Espitia @ chu-Nantes.Fr ${ }^{1}$, P. Cacoub ${ }^{1}$, O. Fain ${ }^{1}$, D. Saadoun ${ }^{1}$ on behalf of NO. ${ }^{1}$ Hopital Saint Antoine, Paris, France

Background: Takayasu arteritis (TA) is a chronic inflammatory large-vessel vasculitis, predominantly affecting the aorta and its main branches

Objectives: To assess safety and efficacy of biologics (i.e. TNF-a antagonists and tocilizumab) in patients with Takayasu arteritis (TA).

Methods: We conducted a retrospective multicenter study in referral centers from Europe and several countries in the world about biological-targeted therapies in Takayasu arteritis during the period from January 2017 to September 2019.

Results: Retrospective multicenter study of characteristics and outcome of 49 TA patients [ $80 \%$ of females; median age 42 [20-55] years] treated by TNF- $a$ antagonists $(80 \%)$ or tocilizumab $(20 \%)$ ] and fulfilling ACR and/or Ishikawa criteria. Factors associated with complete response were assessed. Eighty-eight percent of TA patients were inadequately controlled with, or intolerant to, conventional immunosuppressive therapy [median number of 3 (1-5)]. Overall response (i.e. complete and partial) to biological-targeted treatments at 6 and 12 months was of $75 \%$ and $83 \%$, respectively. There were a significantly lower $\mathrm{C}$-reactive protein levels at initiation of biological-targeted treatments [22 [10-46] mg/l vs 58 [26-76] mg/l, $(p=0.006)]$ and a trend toward lower immunosuppressants drugs used prior biologics $(p=0.054)$ in responders (i.e. complete and/or partial responders) relative to non-responders to biological-targeted treatments. C-reactive protein levels and daily prednisone dosage significantly decreased after 12 months of biological-targeted treatments [ $30 \mathrm{vs} 6 \mathrm{mg} / \mathrm{l}, \mathrm{p}<0.05$ and $15 \mathrm{vs} 7.5 \mathrm{mg}, \mathrm{p}<0.05$, at baseline and at 12 months, respectively]. The 3-year relapse free survival was of $90.9 \%(83.5-$ $99)$ over biologic treatment period compared to $58.7 \%$ (43.3-79.7) $(p=0.0025)$ with DMARDs. No difference was found relative to efficacy between TNF- $a$ antagonists and tocilizumab. After a median follow-up of 24 [2-95] months, $21 \%$ of adverse effects occurred, with biological-targeted treatments discontinuation in $6.6 \%$ of cases.

Conclusion: This nationwide study shows high efficacy of biological-targeted treatments in refractory TA patients with an acceptable safety profile.

Acknowledgments: $\mathrm{NO}$

Disclosure of Interests: Arsene Mekinian: None declared, Mathieu Vautier: None declared, Matthieu resche-rigon: None declared, Lorenzo Dagna Grant/ research support from: Abbvie, BMS, Celgene, Janssen, MSD, Mundipharma Pharmaceuticals, Novartis, Pfizer, Roche, SG, SOBI, Consultant of: Abbvie, Amgen, Biogen, BMS, Celltrion, Novartis, Pfizer, Roche, SG, and SOBI, Savino Sciascia: None declared, olivier.espitia@chu-nantes.fr olivier.espitia@chunantes.fr: None declared, Patrice cacoub: None declared, olivier fain: None declared, david Saadoun: None declared

DOI: 10.1136/annrheumdis-2020-eular.3574

\section{AB0509 \\ SUSPENSIVE EFFICACY OF TOCILIZUMAB IN TREATMENT-NAÏVE PATIENTS WITH TAKAYASU ARTERITIS: TOCITAKA FRENCH PROSPECTIVE MULTICENTER OPEN-LABELLED TRIAL.}

A. Mekinian ${ }^{1}$, D. Saadoun ${ }^{1}$, J. C. N. F. Jerome.Connault @ chu-Nantes.Fr', I. Q.M. F. I-Quere@chu-Montpellier.Fr' , P. Jégo', N. L. F. Nicolas.Limal@aphp. $\mathrm{Fr}^{1}$, W. Wxv ${ }^{1}$, J. E. Gottenberg ${ }^{1}$, M. Vautier ${ }^{1}$, L. S. F. Lea.Savey@aphp. $\mathrm{Fr}^{1}$, P. Cacoub ${ }^{1}, \mathrm{O}$. Fain ${ }^{1}$ on behalf of $\mathrm{n} .{ }^{1} Q S D, Q S D$, France

Objectives: To assess long term efficacy of tocilizumab in treatment-naive patients with Takayasu arteritis (TAK)

Methods: In this multicenter, prospective, open-labelled trial, we aim to evaluate the benefit of adding tocilizumab to steroids in treatment-naïve patients with TAK, on discontinuation of steroids after 6 months of tocilizumab treatment, and to assess relapse-free survival following tocilizumab discontinuation.

Results: Thirteen patients with TAK were included, with a median age of 32 years [19-45] and 12 (92\%) females. Six (54\%) patients met the primary endpoint. Among 11 (85\%) patients which achieved remission at 6 months, 6 (54\%) have reached primary endpoint.. Among the 5 remaining patients which continued steroids, 3 had a prednisone-equivalent dosage $<5 \mathrm{mg} /$ day. A significant decrease of disease activity was observed after 6 months of tocilizumab therapy: decrease of median $\mathrm{NIH}$ scale (3 [3-4] at baseline, versus 1 [0-2] after 6 months; $p<0.001$ ), ITAS-2010 score (5 [2-7] versus 3 [0-8]; $p=0.002)$, and ITAS-A score (7 [4-10] versus 4 [1-15]; $p=0.0001)]$. All patients discontinued tocilizumab after 7 infusions, and no other immunosuppressive drugs was introduced, except for 1 patient which received methotrexate. After 9 and 12 months, respectively $7(54 \%)$ and $6(50 \%)$ patients achieved remission with less than $7.5 \mathrm{mg} /$ day of prednisone, and $9(69 \%)$ and $9(75 \%)$ with doses $<10 \mathrm{mg} /$ day. During the 12 months follow-up after tocilizumab discontinuation, a relapse occurred among 5 patients (45\%) out of 11 in which achieved remission after 6 months of tocilizumab.

No severe AEs were considered related to study treatment and none required tocilizumab interruption or dose reduction. No deaths have occurred during the study period.

Conclusion: Tocilizumab seems an effective steroid sparing therapy in TAK but its effect appears to be suspensive.

Disclosure of Interests: Arsene Mekinian: None declared, david Saadoun: None declared, jerome.connault@chu-nantes.fr jerome.connault@chu-nantes. fr: None declared, i-quere@chu-montpellier.fr i-quere@chu-montpellier.fr: None declared, Patrick Jégo: None declared, nicolas.limal@aphp.fr nicolas.limal@ aphp.fr: None declared, wxv wxv: None declared, Jacques-Eric Gottenberg Grant/research support from: BMS, Pfizer, Consultant of: BMS, Sanofi-Genzyme UCB, Speakers bureau: Abbvie, Eli Lilly and Co., Roche, Sanofi-Genzyme, UCB Mathieu Vautier: None declared, lea.savey@aphp.fr>; lea.savey@aphp.fr>; None declared, Patrice cacoub: None declared, olivier fain: None declared DOI: 10.1136/annrheumdis-2020-eular.4592

\section{AB0510 \\ INFLIXIMAB IS AN EFFECTIVE GLUCOCORTICOID- SPARING TREATMENT FOR TAKAYASU ARTERITIS: RESULTS OF A MULTICENTER OPEN-LABEL PROSPECTIVE STUDY}

P. Mertz ${ }^{1}$, J. F. Kleinmann ${ }^{1}$, M. Lambert ${ }^{2}$, X. Puéchal ${ }^{3}$, T. Martin ${ }^{4}$, J. Sibilia ${ }^{1}$, L. Arnaud'. ' Service de Rhumatologie, Hôpitaux Universitaires de Strasbourg, Laboratoire d'ImmunoRhumatologie Moléculaire, INSERM UMR S1109, Centre National de Références des Maladies Systémiques et Autoimmunes Rares Est Sud-Ouest (RESO), Université de Strasbourg, Strasbourg, France; ${ }^{2}$ Internal Medicine and Clinical Immunology, Centre de Référence des Maladies Autoimmunes Systémiques Rares du Nord et Nord-Ouest de France (CeRAINO), CHU Lille, University Lille, LIRIC, INSERM, Lille, France; ${ }^{3}$ National Referral Center for Rare Systemic Autoimmune Diseases, Hôpital Cochin, AP-HP, Université Paris Descartes, Paris, France; ${ }^{4}$ Service d'Immunologie Clinique, Nouvel Hôpital civil, Strasbourg, France. Centre National de Référence des Maladies Autoimmunes Systémiques Rares Est Sud-Ouest (RESO)-LUPUS, Strasbourg, France

Background: Approximately half of patients with Takayasu Arteritis (TA) have glucocorticoid (GC)-dependency and require the addition of a second-line immunosuppressive treatment.

Objectives: Here, we conducted a multicenter open-label prospective cohort study to assess the efficacy and safety of infliximab originator as a GC-sparing agent in TA. 